\title{
Determination of Nitrogen in Steel
}

\author{
By John L. Hague, Rolf A. Paulson, and Harry A. Bright
}

\begin{abstract}
A rapid semimicro method for the determination of nitrogen in steel is described. A 0.5- to 1.0-gram sample is usually required, and the nitrogen is put into solution as ammonium sulfate by suitable treatment of the sample with sulfuric acid. The ammonia is separated from the bulk of the sample by steam distillation from an alkaline solution. The distillate is collected in boric acid solution, and the nitrogen is determined by titration with 0.01- $N$ acid. Provision is made for the solution of difficultly soluble nitrides. The effect of some of the commonly used alloying elements on the acid solubility of nitrogen compounds in steel is discussed. An accuracy of the order of 0.002 percent of nitrogen or better is indicated for samples containing up to about 0.05 percent of nitrogen and about 0.003 percènt for the range of 0.05 to 0.15 percent of nitrogen. In the lower range of nitrogen contents, 0.002 percent and less, better accuracy can be obtained by attention to pertinent details and the use of a colorimetric method for the determination of the ammonia. A single determination can be completed in about 10 minutes after solution of the sample, and a group of 10 determinations can be carried out in approximately 2 hours.
\end{abstract}

\section{Introduction}

In connection with an investigation on the effect of nitrogen on the hardenability of boroncontaining steel $[8,9]^{1}$ it became necessary to make a large number of nitrogen determinations. The most promising process appeared to be an adaptation of the micro technique to the determination of small percentages of nitrogen involved, as it was apparent that an appreciable saving in time and reagents could be realized.

The methods commonly used for the determination of nitrogen in steel are the "vacuumfusion" method [28] and the "solution-distillation" method. The latter, generally designated as the Allen method [1, 2, 19], depends on converting the nitrides in the test sample to an ammonium salt by solution in diluted hydrochloric or sulfuric acid. The ammonia is usually separated by distillation from an alkaline solution and determined by colorimetric or titrimetric methods. The acidsolution method then consists of two distinct parts: (1) solution of the sample and conversion of the nitrides to ammonium salts and (2) the separation and determination of the ammonia. An accurate method for the separation and determination of

\footnotetext{
${ }^{1}$ Figures in brackets indicate the literature references at the end of this paper.
}

the ammonia is useful only if methods are available to decompose and convert the nitrides present in the sample.

Perchloric acid has been recommended [12] as a useful reagent for the decomposition of refractory nitrides. However, when solutions containing perchloric acid were used in attempts to digest the acid-insoluble portions of stainless steels, low values were sometimes obtained. If the digestions were allowed to proceed to the point of fumes and beyond, the duration of fuming markedly affected the magnitude of the nitrogen losses. Similar difficulties have been noted by others, both in the treatment of steels $[6,15,26]$ and in the digestion of organic materials [29]. It was apparent that perchloric acid, at least under the conditions used, could cause erroneous results; hence the use of this acid was abandoned.

Several methods have been published in which the use of sulfuric acid as a solvent for refractory nitrides is recommended. Cunningham and Hamer [7] advocate filtration of the insoluble nitrides and fuming the filtered residue with sulfuric acid containing a mixture of potassium and copper sulfates. Kempf and Abresch [13] add a small quantity of barium chloride to the sulfuric acid solution of the steel and centrifuge the 
barium sulfate, which has carried down any acidinsoluble residue, from the remainder of the solution. The residue is digested with $\mathrm{H}_{2} \mathrm{SO}_{4}$ and $\mathrm{K}_{2} \mathrm{SO}_{4}$, and the ammonia content of the combined solutions determined. T. Swinden [27] has proposed fuming the sulfuric acid solution of the steel for at least $15 \mathrm{~min}$ after the addition of potassium bisulfate. Brown [4] describes a procedure for the determination of total nitrogen in steel wherein the steel is dissolved in a mixture of diluted sulfuric and phosphoric acids, metallic selenium is added, and, after the removal of water, the mixture is digested at the point of fumes for 2 to $4 \mathrm{hr}$. Newell [21] recommends fuming the sample with sulfuric acid and potassium bisulfate, after the addition of a few drops of hydrogen peroxide, to aid in the decomposition of carbides. In the proposed method the sample is fumed for $4 \mathrm{hr}$ with sulfuric acid to convert the nitrogencontaining compounds, unless it is known that a simpler process will suffice for the material at hand. Hydrogen peroxide is added, as it aids in the decomposition of some materials and does not lead to loss of nitrogen.

Steam distillation from an alkaline solution appears to be the most satisfactory method available for the separation of the ammonia. Beeghly [3] has described a semimicro procedure for the colorimetric determination of nitrogen in steel using this separation. In the procedure of Kempf and Abresch [14] the steam-distillation separation is used. The ammonia is collected in an excess of standard acid, and the excess is titrated with standard alkali.

The use of the apparatus devised by Parnas and Wagner $[22,23]$ for the separation of ammonia by steam distillation is recommended. The ammonia is collected in a dilute boric acid [30] solution and titrated directly with standard acid, using a methyl red-bromcresol green indicator mixture proposed by Ma and Zuazaga [20]. The volume of the ammonia distillate is kept small, approximately $15 \mathrm{ml}$ of solution being collected. This small volume contributes to a small titration blank and to the sharpness of the indicator change. The particular advantages of the proposed method are rapidity and ease of operation. An individual distillation and titration may be completed in approximately $10 \mathrm{~min}$. The total time required for an analysis depends principally upon the solution procedure required.

\section{Reagents}

Diluted sulfuric acid $(1+2)$.

Hydrogen peroxide, (30-percent).

Boric acid solution, (20 g per $l$ ).-Dissolve $5 \mathrm{~g}$ of $\mathrm{H}_{3} \mathrm{BO}_{3}$ in $250 \mathrm{ml}$ of water.

Sodium hydroxide solution (30-percent).-Dissolve $240 \mathrm{~g}$ of sodium hydroxide in $560 \mathrm{ml}$ of ammoniafree water.

Indicator solution.-Dissolve $0.1 \mathrm{~g}$ of bromcresol green in $100 \mathrm{ml}$ of 95-percent ethyl alcohol. Dissolve $0.1 \mathrm{~g}$ of methyl red in $100 \mathrm{ml}$ of 95percent ethyl alcohol. Mix five parts of bromcresol green solution with one part of methyl red solution for use.

Standard hydrochloric acid $(0.01-N)$.- This solution can be prepared by accurately diluting a standardized $0.1-N$ hydrochloric acid solution with distilled water. The factor of the prepared solution can be checked against sulfamic acid through $\mathrm{NaOH}$ solution using the mixed indicator, or can be compared directly, using the mixed indicator, with standard borax solution [18].

\section{Apparatus and Reagents}

\section{Apparatus}

Vycor micro-Kjeldahl digestion flasks, 30-ml volume (Corning Glass Works No. 15440).

10-ml microburette.

Distillation apparatus.-Parnas and Wagner type, as illustrated in figure 1. This apparatus is standard micro-Kjeldahl equipment except for the distilling flask (D). The lower bulb of this flask is somewhat larger (175 ml instead of the usual $90 \mathrm{ml}$ ) in volume than ordinarily supplied and can be obtained on special order. ${ }^{2}$ The steam generator (A) is a 1-liter round-bottomed Pyrex flask, filled two-thirds to three-quarters full of distilled water. A few chips of silicon carbide are added to insure even boiling, and 4 or $5 \mathrm{ml}$ of sulfuric acid are added to fix any small amount of ammonia in the water. The steam generator is connected to the side arm of a cylindrical trap (B) of about 300-ml volume. This trap has a drain at the bottom, closed by a short length of rubber tubing and a pinchcock. A piece of glass tubing, bent at a right angle, is connected to the trap with a rubber stopper and to the steam inlet tube of the distilling

\footnotetext{
${ }^{2}$ Suitable flasks have been secured from A. H. Thomas Co., Philadelphia, Pa., and from Scientific Glass Apparatus Co., Bloomfield, N. J.
} 
flask (D) with a short piece of rubber tubing. The steam inlet tube is also connected to a small funnel (C) used to introduce the sample and alkali into the flask. The flask (D) is vacuum-jacketed, and the exit end consists of an antifoaming bulb and trap. The exit end is connected by rubber tubing to a water-jacketed silver-tube condenser (E), and the distillate is caught in a 50-ml Erlenmeyer flask (F).

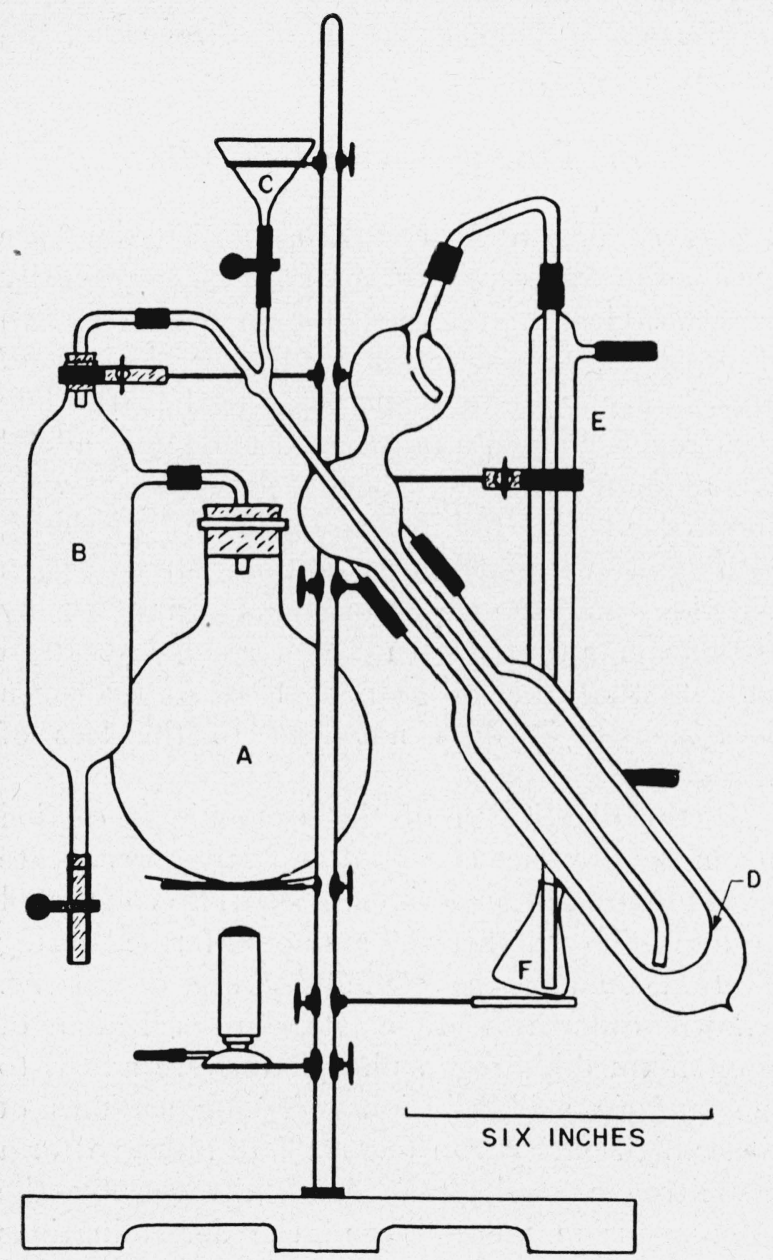

Figure 1. Distillation apparatus.

Ammonia-free water.-Satisfactory water can be prepared by distillation from a diluted sulfuric acid solution.

Nessler's reagent.-Dissolve $50 \mathrm{~g}$ of potassium iodide in a minimum volume of cold water (approximately $35 \mathrm{ml}$ ) and add slowly, with good mixing, a saturated solution of mercuric chloride until the first slight precipitate of red mercuric iodide persists. Add $400 \mathrm{ml}$ of a clear $9-\mathrm{N}$
$\mathrm{NaOH}$ solution $(360 \mathrm{~g} /$ liter $)$, dilute to 1 liter with ammonia-free water, and allow the reagent to stand until clear. Decant the clear supernatant liquid for use.

\section{Procedure}

Transfer $0.5 \mathrm{~g}$ of the sample to a Vycor microKjeldahl flask and add $10 \mathrm{ml}$ of diluted $\mathrm{H}_{2} \mathrm{SO}_{4}$ $(1+2),{ }^{3}$ one or two drops of hydrofluoric acid $(48 \%)$, and a few drops of hydrogen peroxide $(30 \%) .^{4} \quad$ Place the flask over a small flame on a digestion rack until solution action ceases. If the material does not contain acid-insoluble nitrides, the acid solution is now ready for the distillation of the ammonia.

Some types of steel contain acid-insoluble material that can be decomposed by a short, vigorous fuming after the addition of hydrogen peroxide. For these materials, remove the flask from the digestion rack, and while holding the neck of the flask in a test-tube holder or clamp, warm the solution with constant swirling over a low flame. When most of the water has been driven off, cool the flask under tap water, and add $1 \mathrm{ml}$ of hydrogen peroxide $(30 \%)$. Continue heating the solution, with a swirling motion, to the point of fumes and fume vigorously for a minute or two. Cool under tap water, add $10 \mathrm{ml}$ of ammonia-free water, and warm to dissolve most of the separated salts. The solution is now ready for distillation of the ammonia.

The sulfuric acid mixtures of some materials, particularly those containing columbium and titanium, also certain other types that have been heat-treated, contain refractory nitrides that must be treated more vigorously to effect solution. After reaching the fuming point, return the flask to the digestion rack and continue the digestion for $3 \frac{1}{2}$ to $4 \mathrm{hr}$. The temperature should be sufficiently high to give some refluxing action with the sulfuric acid, and the flask should be rotated occasionally to prevent excessive caking. Remove the flask from the rack, cool under tap water, and add $10 \mathrm{ml}$ of ammonia-free water. Warm the flask gently to loosen the salts and cool. The solution is now ready for distillation of the ammonia.

3 Carbon and low alloy steels usually dissolve more quickly if $5 \mathrm{ml}$ of water is also added. $15 \mathrm{ml}$ of diluted $\mathrm{H}_{2} \mathrm{SO}_{4}(1+3)$ can be used with these types of material.

${ }^{4}$ Hydrogen peroxide sometimes makes high-chromium steels passive, and this addition should not be made on these types until the sample has reacted with the acid. 
Transfer $5 \mathrm{ml}$ of the boric acid solution (this need not be accurately measured) to a 50-ml Pyrex Erlenmeyer flask and add four drops of indicator solution. The distillation apparatus should be steamed-out thoroughly for about $30 \mathrm{~min}$ before the first determination is made.

Open the pinch clamps of the introductory funnel (C) and the outlet tube (B), pour the sulfuric acid solution of the sample through the funnel, and rinse the digestion flask two or three times with small portions of ammonia-free water. Light the burner under the steam generator, add $25 \mathrm{ml}$ of sodium hydroxide solution $(30 \%)$ through the introductory funnel, and close the pinchcock. Suspend the flask of boric acid under the condenser. As soon as steam issues freely from the drain tube of flask (B), close the pinchcock and immediately raise the flask of boric acid to the proper level. Time the distillation by noting the time the top of the condenser (E) becomes warm, and continue the distillation for $3 \mathrm{~min}$ at such a rate that 3 to $5 \mathrm{ml}$ per minute of condensate is collected. Lower the receiver containing the boric acid and continue the distillation for $1 \mathrm{~min}$. Rinse the condenser tip with 1 or $2 \mathrm{ml}$ of water and extinguish the burner. Titrate the boric acid solution with the standard $0.01-N \mathrm{HCl}$ solution to a clear pink end point.

Correct the volume of $0.01-N$ hydrochloric acid required in titrating the boric acid solution by the volume of standard acid required in a blank run, preferably obtained by carrying a $0.5-\mathrm{g}$ sample of nitrogen-free steel through all steps of the procedure. The reagents used in this procedure gave a blank of approximately $0.15 \mathrm{ml}$ of $0.01-N$ hydrochloric acid. The calculation is made as follows:

$$
\% \text { nitrogen }=\frac{\begin{array}{c}
\text { net volume of } 0.01-N \mathrm{HCl} \times \\
(0.000140) \times 100
\end{array}}{0.5}
$$

In the range of 0.002 percent of nitrogen and less, the determination can be conveniently completed by using a modification of the photometric procedure described by Beeghly. Collect approximately $9.5 \mathrm{ml}$ of distillate in each of two Kromatrol or Klett colorimeter tubes, add $0.2 \mathrm{ml}$ of Nessler's reagent, dilute to the $10-\mathrm{ml}$ mark, and mix well. Measure the transmittancy or absorbency of the solution at 430 to $460 \mu$, after allowing the tube to stand $5 \mathrm{~min}$. Determine the amount of nitrogen by use of a calibration curve prepared from data obtained from measurements of known quantities ( 0 to $20 \mu \mathrm{g}$ ) of nitrogen. The calibrating solutions can be prepared by aliquoting portions of a standardized solution af ammonium chloride. Correct the value obtained for a blank determined by carrying all the reagents used through all steps of the procedure [10]. With water purified by distillation from a weak sulfuric acid solution, the reagents used in testing the procedure gave a blank approximating 0.0003 percent of nitrogen on the basis of a $1-\mathrm{g}$ sample.

\section{Discussion and Results}

Larger amounts of hydrogen peroxide are specified in the procedure than are used ordinarily in micro-Kjeldahl digestions for the determination of nitrogen. To determine whether the use of these larger amounts of peroxide lead to the loss of nitrogen, known quantities of ammonia, added as ammonium dihydrogen phosphate, were digested at the fuming point of sulfuric acid, with and without the addition of hydrogen peroxide, and the determinations completed by distillation and titration. The results obtained indicate that the addition of $1 \mathrm{ml}$ of hydrogen peroxide $(30 \%)$ does not lead to the loss of nitrogen.

As the distillation of the ammonia is carried out in the presence of a relatively large precipitate of iron hydroxide, experiments were also conducted to determine whether the ammonia formed during solution could be recovered under these conditions. Known quantities of a standard solution of ammonium dihydrogen phosphate were added to the sulfuric acid solutions of $0.5-\mathrm{g}$ samples of either high-purity iron $(0.0005 \%$ of nitrogen $)$ or a low-nitrogen steel $(0.003 \%$ of nitrogen by the vacuum-fusion method) and the determinations completed as described in the recommended procedure. The values obtained indicate an accuracy of \pm 0.001 to 0.002 percent of nitrogen for samples containing up to about 0.05 percent of nitrogen, and an accuracy of \pm 0.002 to 0.003 percent of nitrogen in the range of 0.05 to 0.15 percent of nitrogen.

The accuracy actually obtained in a determination on a steel sample is somewhat more difficult to assess, since good "check" values on replicate determinations may indicate only that the samples 
are decomposed to the same extent. However, a comparison of values obtained by the recommended procedure with those obtained by the vacuum-fusion process indicates that the accuracy of the method is very close to that indicated by the experiments on synthetic samples described in the preceding paragraph.

The problem of checking the accuracy of the photometric procedure for low nitrogen contents is also a difficult one. However, samples from two experimental ingots of high-purity iron gave values of 0.0007 (average deviation of 10 determinations 0.0003 ) and 0.0012 percent of nitrogen (average deviation of 10 determinations 0.0002 ). Comparison of these values with those obtained by vacuum-fusion (0.0004 and 0.0009 percent of nitrogen) indicates the accuracy to be better than 0.0005 percent of nitrogen in this low range.

A comparison of the values obtained by the recommended procedure (section III) with those obtained by the vacuum-fusion procedure over a period of several years revealed several interesting sources of error that can be encountered in the determination of nitrogen.

In one instance, a series of steels in the form of thin, flat sheets was received for analysis. The first analyses by the chemical procedure indicated a value of about 0.002 to 0.003 percent of nitrogen, whereas those obtained by the vacuum-fusion process indicated a value on the order of 0.005 to 0.006 percent of nitrogen. An exchange of the prepared samples confirmed the approximate difference, which was finally traced to the fact that the samples originally used for the vacuumfusion analyses had been "surface cleaned" on a high-speed grinding wheel. With the large surfaceto-weight ratio of this type of sample, apparently sufficient "nitriding" of the surface had occurred, due to the heating of the sample during grinding, to cause significant error, for when the determinations were repeated by both methods on "pickled" samples, concordant values in the neighborhood of 0.002 to 0.003 percent of nitrogen were obtained. Such difficulties have been encountered by others [17].

In another case, a sample that had been annealed under helium was received for confirmation of a nitrogen content of about 0.0003 percent. Using the straight acid solution technique usually employed in the "Allen-type" methods and the semimicro adaptation of the Nessler colorimetric procedure to determine the ammonia, a value closely approximating 0.0003 percent was obtained. However, when the sample was digested for $4 \mathrm{hrs}$ at the fuming point with sulfuric acid, a value of 0.002 -percent nitrogen resulted. Obviously, not all of the nitrogen compounds were converted to ammonia by solution in diluted acid, and similar instances can be found in the literature $[5,11,16,25]$.

A detailed study of various solution techniques was made on NBS Standard Sample 32d, a chromium-nickel (SAE 3140) steel that contains refractory nitrides, and the results are summarized in figure 2. The horizontal bar represents the maximum and minimum value obtained for the particular solution procedure specified, and the vertical bar gives the average value obtained for the number of determinations specified in parentheses.

Titanium is known to form nitrogen-containing compounds in steel that are quite insoluble in diluted acid or alkali. The behavior of NBS Standard Sample 121a, a titanium-bearing corrosion-resisting type of steel, is typical of a number of steels of this type examined [24] and is summarized in figure 3 . The average value of 0.015 percent nitrogen obtained for the samples fumed $4 \mathrm{hrs}$ compares favorably with the certificate value of 0.014 percent. Figure 4 illustrates the behavior of a type 347 corrosion-resisting steel containing approximately 0.8 percent of Columbium and is typical of the behavior of the samples of this type of steel examined. The loss of nitrogen by fuming solutions containing perchloric acid is also illustrated.

Figure 5 presents the behavior of NBS Standard Sample 50b, an $18 \mathrm{~W}, 4 \mathrm{Cr}, 1 \mathrm{~V}$ type of tungsten tool-steel. The short, vigorous fuming (temperature effect) and the addition of peroxide appear to aid in the decomposition of this steel, but a sufficient number of samples of this type have not been examined to allow the recommendation. of the short fuming procedure for general use. The nitrogen compounds in this type of material are generally only partly soluble in diluted acid.

Many carbon and alloy steels will, for all practical purposes, yield the total nitrogen content by simple solution in diluted sulfuric acid. However, those containing even small amounts of an element such as titanium frequently do not yield all their nitrogen under these conditions. The 


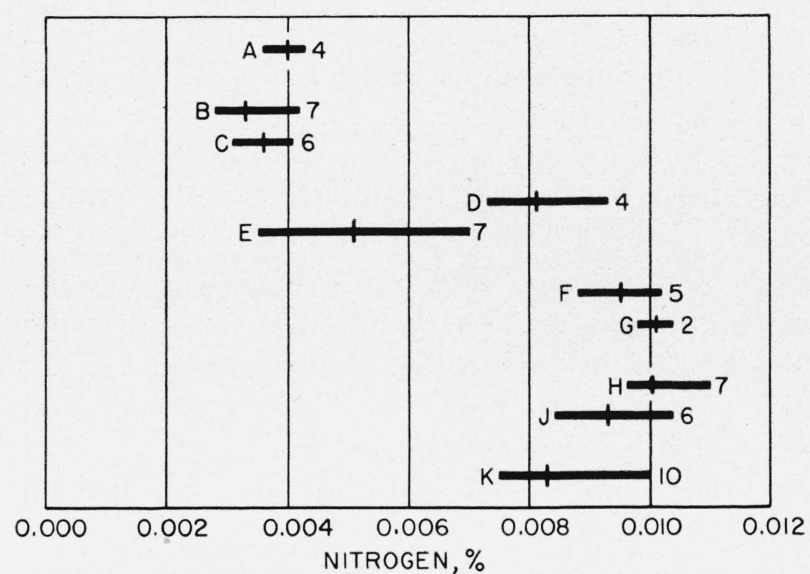

Figure 2. NBS standard sample 32d $\mathrm{Cr}-\mathrm{Ni}$ steel (SAE 3140).

$A$, Allen method, $\mathrm{HCl}(1+1) ; B, \mathrm{H}_{2} \mathrm{SO}_{4}$ solution; $C, \mathrm{H}_{2} \mathrm{SO}_{4}$ solution plus $\mathrm{H}_{2} \mathrm{O}_{2} ; D, \mathrm{H}_{2} \mathrm{SO}_{4}$, to fumes; $E, \mathrm{H}_{2} \mathrm{SO}_{4}$, to fumes plus $\mathrm{H}_{2} \mathrm{O}_{2} ; F, \mathrm{H}_{2} \mathrm{SO}_{4}$, fumed $1 / 2 \mathrm{hr} ; \theta, \mathrm{H}_{2} \mathrm{SO}_{4}$, fumed $1 / 2 \mathrm{hr}$ plus $\mathrm{H}_{2} \mathrm{O}_{2} ; H, \mathrm{H}_{2} \mathrm{SO}_{4}$, fumed $4 \mathrm{hr} ; J, \mathrm{H}_{2} \mathrm{SO}_{4}$, fumed $4 \mathrm{hr}$ plus $\mathrm{H}_{2} \mathrm{O}_{2} ; \mathrm{K}$, vacuum fusion.

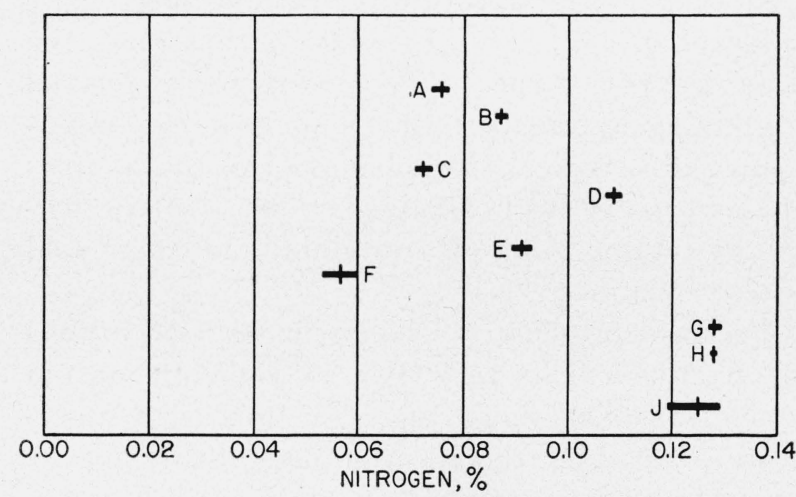

Figure 4. Crucible Steel Company standard 17 (18-Cr, 11-Ni, 0.8-Cb).

$A$, Solution in $\mathrm{H}_{2} \mathrm{SO}_{4} ; B$, Solution in $\mathrm{H}_{2} \mathrm{SO}_{4}$ plus $\mathrm{H}_{2} \mathrm{O}_{2} ; C, \mathrm{H}_{2} \mathrm{SO}_{4}$, fumed $2 \mathrm{hr} ; D, \mathrm{H}_{2} \mathrm{SO}_{4}$ fumed $2 \mathrm{hr}$ plus $\mathrm{H}_{2} \mathrm{O}_{2} ; E, \mathrm{H}_{2} \mathrm{SO}_{4}, \mathrm{H}_{3} \mathrm{PO}_{4}, \mathrm{HClO}_{4}$, fumed 15 min; $F, \mathrm{H}_{2} \mathrm{SO}_{4}, \mathrm{H}_{3} \mathrm{PO}_{4}, \mathrm{HClO}_{4}$, fumed $3 \mathrm{hr} ; G, \mathrm{H}_{2} \mathrm{SO}_{4}$, fumed $4 \mathrm{hr} ; H$, $\mathrm{H}_{2} \mathrm{SO}_{4}$, fumed $4 \mathrm{hr}$ plus $\mathrm{H}_{2} \mathrm{O}_{2}: J$, vacuum fusion.

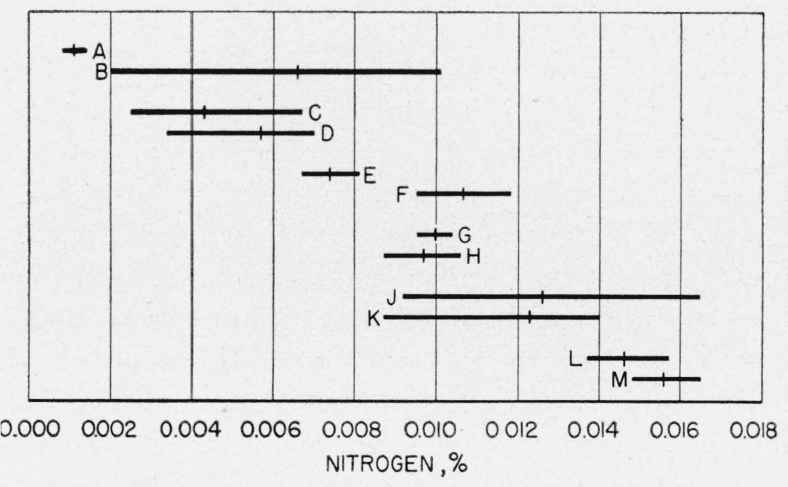

Frgure 3. NBS standard sample 121A (18-Cr, 10-Ni, $0.4 \mathrm{Ti}$ steel).

$A, \mathrm{H}_{2} \mathrm{SO}_{4}$ solution; $B, \mathrm{H}_{2} \mathrm{SO}_{4}$ solution plus $\mathrm{H}_{2} \mathrm{O}_{2} ; C, \mathrm{H}_{2} \mathrm{SO}_{4}$, to fumes; $D$, $\mathrm{H}_{2} \mathrm{SO}_{4}$, to fumes plus $\mathrm{H}_{2} \mathrm{O}_{2} ; E, \mathrm{H}_{2} \mathrm{SO}_{4}$, to strong fumes; $F, \mathrm{H}_{2} \mathrm{SO}_{4}$, to strong fumes plus $\mathrm{H}_{2} \mathrm{O}_{2} ; G, \mathrm{H}_{2} \mathrm{SO}_{4}$, fumed strongly $5 \mathrm{~min} ; \mathrm{H}, \mathrm{H}_{2} \mathrm{SO}_{4}$, fumed strongly 5 min plus $\mathrm{H}_{2} \mathrm{O}_{2} ; \mathrm{J}, \mathrm{H}_{2} \mathrm{SO}_{4}$, fumed $1 / 2 \mathrm{hr} ; \mathrm{K}, \mathrm{H}_{2} \mathrm{SO}_{4}$, fumed $1 / 2 \mathrm{hr}$ plus $\mathrm{H}_{2} \mathrm{O}_{2} ; L$, $\mathrm{H}_{2} \mathrm{SO}_{4}$, fumed $4 \mathrm{hr} ; M, \mathrm{H}_{2} \mathrm{SO}_{4}$, fumed $4 \mathrm{hr}$ plus $\mathrm{H}_{2} \mathrm{O}_{2}$.

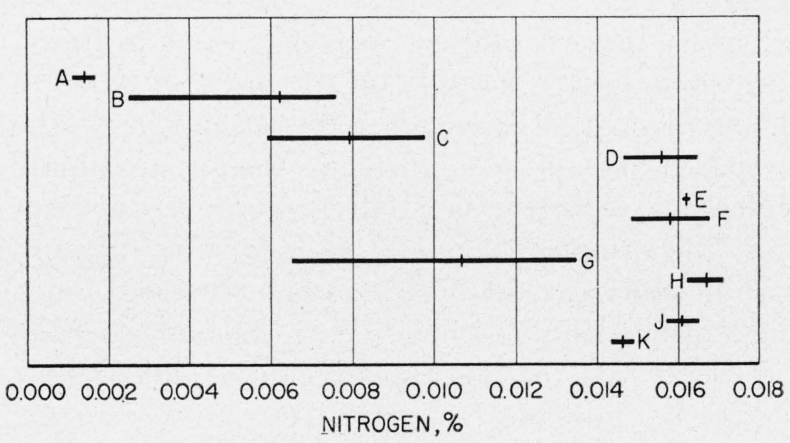

Figure 5. NBS standard sample $50 B(18-W, 4-\mathrm{Cr}, 1-V$ steel).

$A, \mathrm{H}_{2} \mathrm{SO}_{4}$ solution; $B, \mathrm{H}_{2} \mathrm{SO}_{4}$ solution plus $\mathrm{H}_{2} \mathrm{O}_{2} ; C, \mathrm{H}_{2} \mathrm{SO}_{4}$, to strong fumes; $D, \mathrm{H}_{2} \mathrm{SO}_{4}$, to strong fumes plus $\mathrm{H}_{2} \mathrm{O}_{3} ; E, \mathrm{H}_{2} \mathrm{SO}_{4}$, fumed strongly $5 \mathrm{~min} ; F$, $\mathrm{H}_{2} \mathrm{SO}_{4}$, fumed strongly 5 min plus $\mathrm{H}_{2} \mathrm{O}_{2} ; G, \mathrm{H}_{2} \mathrm{SO}_{4}$, fumed $1 / 2 \mathrm{hr} ; H, \mathrm{H}_{2} \mathrm{SO}_{4}$, fumed $1 / 2 \mathrm{hr}$ plus $\mathrm{H}_{2} \mathrm{O}_{2} ; J, \mathrm{H}_{2} \mathrm{SO}_{4}$, fumed $4 \mathrm{hr} ; \mathrm{K}, \mathrm{H}_{2} \mathrm{SO}_{4}$, fumed $4 \mathrm{hr}$ plus $\mathrm{H}_{2} \mathrm{O}_{2}$. 
short, vigorous fuming with sulfuric acid and peroxide appears to aid in the decomposition of this type of material. These rapid solution procedures should prove useful where they can be shown by experiment to be applicable, especially in plant laboratories where the elapsed time of analysis is important.

The authors are especially indebted to H. E. Cleaves, Chief of the Chemical Metallurgy Section, whose staff determined, by the vacuumfusion method, the nitrogen content of many of the samples used in testing the procedure; and to K. D. Fleischer, formerly of the Chemistry Division, for valuable assistance in the early stages of the development of the method.

\section{References}

[1] A. H. Allen, J. Iron Steel Inst. \%, 480 (1879).

[2] A. H. Allen, J. Iron Steel Inst. 8, 181 (1880).

[3] H. F. Beeghly, Ind. Eng. Chem., Anal. Ed. 14, 137 (1942).

[4] W. D. Brown, Proc. Conf. Natl. Open Hearth Comm., Iron and Steel Div., Am. Inst. Mining Met. Engrs. 27, 166 (1944).

[5] W. D. Brown, Proc. Conf. Natl. Open Hearth Comm., Iron and Steel Div., Am. Inst. Mining Met. Engrs. 27, 168 (1944).

[6] Chemists of U. S. Steel Corp., Sampling and analysis of carbon and alloy steels, p. 288 (Reinhold Publishing Corp., New York, N. Y., 1938).

[7] T. R. Cunningham and H. L. Hamer, Ind. Eng. Chem., Anal. Ed. 11, 303 (1939).

[8] T. G. Digges, Influence of nitrogen on some properties of steels with and without boron and titanium additions, OSRD No. 1506, Serial No. M-84 (June 3, 1943).
[9] T. G. Digges and F. M. Reinhart, Trans. Am. Soc. Metals 40, 1124 (1948).

[10] J. L. Hague, Proc. Am. Soc. Testing Materials 44, 715 (1944).

[11] C. Holthaus and W. Holtmann, Arch. Eisenhüttenw. 17, 247 (1944).

[12] C. M. Johnson, Iron Age 134, No. 4, 10 (1934).

[13] H. Kempf and K. Abresch, Arch. Eisenhüttenw. 14, 255 (1940).

[14] H. Kempf and K. Abresch, Arch. Eisenhüttenw. 14, 258 (1940).

[15] H. Kempf and K. Abresch, Arch. Eisenhüttenw. 17, 121 (1943).

[16] H. Kempf and K. Abresch, Arch. Eisenhüttenw. 17, 261 (1944).

[17] H. Kempf and A. Neuberger, Arch. Eisenhüttenw. 17, 5 (1943).

[18] I. M. Kolthoff and N. H. Furman, Volumetric analysis 2,94 to 96 (John Wiley \& Sons, Inc., New York, N. Y., 1929).

[19] G. C. Lloyd, Sixth report on the heterogenity of steel ingots, Iron and Steel Inst. (1935). Speical Report No. 9, Section 7, p. 121.

[20] T. S. Ma and G. Zuazaga, Ind. Eng. Chem., Anal. Ed. 14, 280 (1942).

[21] W. C. Newell, J. Iron Steel Inst. 152, 333 (1945).

[22] J. K. Parnas, Z. anal. Chem. 114, 261 (1938).

[23] J. K. Parnas and R. Wagner, Biochem. Z. 125, 253 (1921).

[24] S. J. Rosenberg and J. H. Darr, J. Research NBS 40, 324 (1948).

[25] T. Swinden, J. Iron Steel Inst. 148, No. 2, 306 (1943).

[26] T. Swinden, J. Iron Steel Inst. 148, No. 2, 312 (1943).

[27] T. Swinden, J. Iron Steel Inst. 148, No. 2, 316 (1943).

[28] H. C. Vacher and L. Jordan, BS J. Research 1, 375 (1931).

[29] L. F. Wicks and H. I. Firminger, Ind. Eng. Chem., Anal. Ed. 14, 760 (1942).

[30] L. W. Winkler, Z. angew. Chem. 26, 231 (1913).

Washington, May 10, 1949. 